
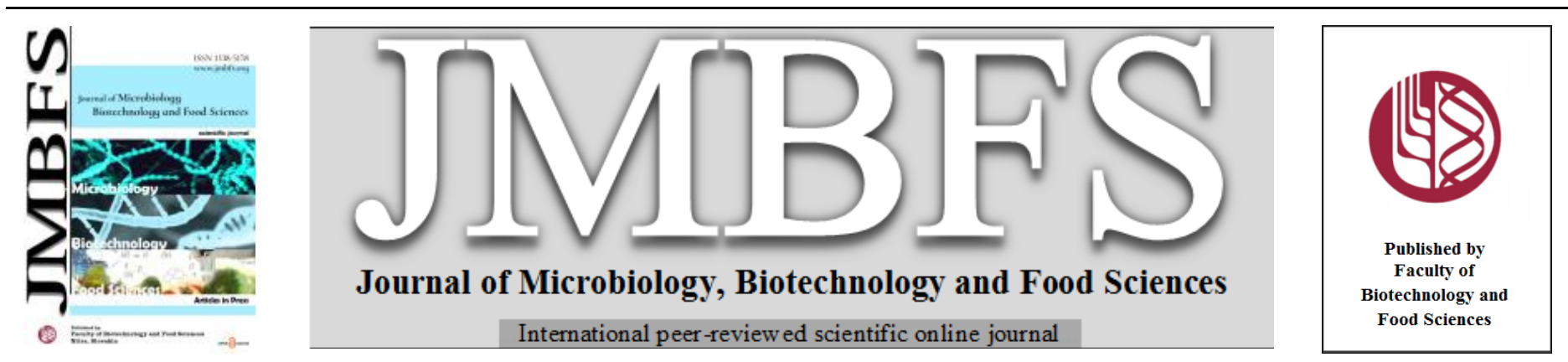

\title{
THE EFFECTS OF ORIENTIN ON THP-1 CELLS INFECTED BY DENV2
}

\section{Bernadette Xin-Jie Tune ${ }^{l}$, Anna Pick-Kiong Ling ${ }^{1 *}$, Kenny Gah-Leong Voon ${ }^{2}$, Ying-Pei Wong ${ }^{1}$}

Address(es): Anna Pick Kiong Ling,

${ }^{1}$ Division of Applied Biomedical Sciences and Biotechnology, School of Health Sciences, International Medical University, Bukit Jalil, 57000 Kuala Lumpur, Malaysia. ${ }^{2}$ Department of Pathology, School of Medicine, International Medical University, Bukit Jalil, 57000 Kuala Lumpur, Malaysia.

*Corresponding author: anna ling@imu.edu.my

https://doi.org/10.55251/jmbfs.4289

\section{ARTICLE INFO}

Received 1.2. 2021

Revised 8. 12. 2021

Accepted 8. 12. 2021

Published 1. 4. 2022

Regular article

OPEN $\partial_{\text {ACCESS }}$

\begin{abstract}
Orientin, a flavonoid known for its significant antioxidative properties, has also shown to possess antiviral properties against some viruses. Nevertheless, up to now, there was no report on its ability against dengue virus. This study investigated the effects of orientin against DENV2 infecting human monocyte, THP-1 cells. THP-1 cells infected with DENV2 $\left(3.16 \times 10^{2} \mathrm{TCID}_{50} / \mathrm{mL}\right)$ were treated with a maximum non-toxic dose (MNTD) of orientin $(0.053 \pm 0.006 \mu \mathrm{M})$ for two days. Cytopathic effect (CPE) formation was observed after two days, followed by measurement of the percentage of cell viability using 3-(4,5- Dimethylthiazol-2-yl)-2,5-diphenyltetrazolium bromide (MTT) assay. The treatment was compared to cells infected with DENV2 only, cells treated with orientin at MNTD only, and control cells. The MNTD of orientin on THP- 1 cells were determined to be $0.053 \pm 0.006 \mu \mathrm{M}$. Treatment of DENV2 infected THP-1 cells with the MNTD of orientin showed CPE formation similar to the THP-1 cells infected with DENV2 only. The MTT assay showed that orientin did not exhibit antiviral activity against DENV2 infecting THP-1 cells. Percentage of cell viability of the orientin treated cells and DENV2infected cells were not significantly different. Orientin at MNTD does not exhibit antiviral effects on THP-1 cells infected with DENV2.
\end{abstract}

Keywords: Antiviral; Dengue; Flavonoids; Ocimum sanctum; Orientin

\section{INTRODUCTION}

Dengue fever is the most common arthropod-borne viral disease which is endemic in more than 100 countries (Ahmad et al., 2018). The disease is caused by a flavivirus known as dengue virus (DENV) and is transmitted by the bite of an infected female Aedes aegypti or Aedes albopictus mosquito. The virus is known to have four distinct serotypes which are DENV1, DENV2, DENV3, and DENV4, with a study concluding the emergence of a distinct fifth serotype in Sarawak, Malaysia (Mustafa et al., 2015). Symptoms of dengue fever include high fevers, headache, pain in the joints and behind the eyes, vomiting, and inflammation of the glands. Progression of the disease will present more severe symptoms such as respiratory distress, fluid accumulation, petechiae, severe bleeding, organ damage, and death (Singh \& Rawat 2017). The stages of dengue fever are febrile, critical, and recovery. Primary infections are usually self-limiting, and supportive measures are adequate for patient treatment. Symptomatic relief is provided for patients undergoing the febrile stage (Rajaoakse $\boldsymbol{e t}$ al., 2012). The critical stage usually comprises symptoms of dengue hemorrhagic fever (DHF) and dengue shock syndrome (DSS) (Lum et al., 2014). Close monitoring of the patient is necessary in the critical period to minimize the risks of fatality (Rajapakse et al., 2012). DHF is largely associated by hemorrhagic features such as plasma leakage due to increased vascular permeability, and thrombocytopenia (Bäck and Lundkvist, 2013). Progress from DHF to DSS presents occurrence of cardiovascular compromise due to plasma leakage into interstitial spaces which eventually leads to shock (Bäck and Lundkvist, 2013). Warning signs of DSS include rapid increase of hematocrit, severe abdominal pain, persistent vomiting, and severely low or absent blood pressure (Gubler, 2002). Urgent fluid replacement is necessary to prevent fatality due to DSS. Dengue occurrences in Malaysia is typically caused by DENV1, DENV2, and DENV3. DENV4 occurrences are not as common (Mohd Zaki et al., 2014). However, the South-East Asian strain of DENV2 presents a higher occurrence of severe dengue (Bäck and Lundkvist, 2013).

Despite the countless efforts to curb dengue, it has not been very successful. In 2016, Sanofi Pasteur released a dengue vaccine (Dengvaxia ${ }^{\circledR}$, CYD-TDV) (Scott, 2016). Nevertheless, administration of the vaccine showed increased risk of hospitalization on seronegative patients, yet a protective effect on seropositive patients (Deen, 2016). Although the exact mechanism on why the vaccine failed is still unknown, it was thought to be caused by a dengue virus specific phenomena call antibody-dependent enhancement (ADE) (Halstead, 2016). ADE occurs in patients who have gained immunity to a serotype of DENV from a primary infection. A secondary heterotypic infection will not yield the same results. Preexisting antibodies will cross-react with the virus, and enhance infection of the virus on Fc $\gamma$ receptor-carrying cells (Bäck and Lundkvist, 2013), which therefore increases virus infection efficiency by increasing membrane fusion activity and reducing antiviral response in the early viral life cycles (Flipse et al., 2016). ADE is also associated with higher risks of DHF and DSS. Hence, until today, there has been no effective antiviral agent against dengue virus.

Due to the shortcomings of vaccines, many have studied on the use and effectiveness of utilizing traditional or alternative medicines to combat dengue. Natural compounds such as polyphenols, terpenes, and flavonoids are widely claimed to possess antiviral and antimicrobial properties. One of the most popular home remedies against dengue is the leaf extract of Carica papaya or papaya leaves. However, research has concluded that the extract does not work as an antiviral agent, and more as a means to relief thrombocytopenia (Ahmad et al., 2011). Other examples of traditional herbs for dengue treatment include Azadirachta indica, Hippophae rhamnoides, Andrographis paniculata, and Ocimum sanctum (Singh and Rawat, 2017). Previous studies were conducted on the methanolic extracts of Ocimum sanctum, an Ayurvedic herd commonly known as Holy Basil or Tulsi (Pattanayak et al. 2010). The extract showed anti-DENV1 activity, which could be contributed by the flavonoid content of the extract (Ling et al., 2014; Tang et al., 2012). The flavonoid content in $O$. sanctum was determined to be $88.6 \%$, of which orientin and vicenin were reported to be the two main flavonoids (Tang et al., 2012).

Orientin is claimed to possess a multitude of properties including antioxidative, antiviral, antibacterial, and anti-inflammatory properties among others. Orientin is a C-glycosyl compound and is best known for its powerful antioxidative property (Khan, 2012). The compound is derived from luteolin, also an antioxidant with anti-proliferative and anti-inflammatory properties (Lupu and Menendez, 2006). The structure of orientin (Figure 1) comprises of a chroman nucleus and various hydroxyl group substitutions, the number of hydroxyl groups and the arrangements correlate with radical scavenging activity, hence contributing to the potent antioxidative property of orientin (Al-sehemi and Irfan, 2017). 
<smiles>O=c1cc(Cc2ccc(O)c(O)c2)oc2c(C3OC(CO)C(O)C(O)C3O)c(O)ccc12</smiles>

Figure 1 Structure of orientin

In the context of a dengue virus infection, the antioxidative, antiviral, and antiinflammatory properties of orientin are of interest. Dengue virus infections are known to cause excess production of reactive species that can disturb the redox balance and cause cell damage and cell death (Valero et al., 2013; Krylova et al. 2016), hence the antioxidative property of orientin might be able to reduce reactive species induced cell damage. Furthermore, the antioxidative property of orientin could combat overproduction of nitric oxide (NO) during dengue virus infection of monocyte cells, and thus reduce inflammation caused by NO (Valero $\boldsymbol{e t}$ al. 2013; Guzik et al., 2003)

As for antiviral effects of orientin, reports on antiviral activity against DENV1 (Ling et al., 2014), Para3 virus (Li et al., 2002), and Herpes Simplex Virus-2 (HSV-2) (Boominathan et al., 2014), and respiratory syncytial virus (RSV) (Ooi et al., 2014) have been made. The activity against HSV was exhibited by a mixture of flavonoids (rutin, quercetin, kaempferol, and orientin), which may suggest possible synergistic antivirus effects of orientin with other flavonoids (Boominathan et al., 2014). Although exact mechanisms of action (MOA) are still largely unknown, it was suggested that similar MOA may be shared by flavonoids of similar structure. Zandi et al. (2011) reported on the antiviral activity of quercetin against DENV2 via inhibition of viral polymerase, and viral nucleic acids or viral capsids. Other reports also mentioned MOA via inhibition of cell membrane fusion by inhibiting formation of proteoglycans, inhibition of reverse transcriptase enzyme of RNA viruses, as well as other viral enzymes including DNA polymerase and integrase (Prasain et al., 2010; Ahmad et al., 2015; Cushnie and Lamb, 2005). Studies on luteolin also exhibited extracellular virucidal activity, and post-entry inhibition (Fan et al., 2016). Although the exact antiviral MOA of orientin are not yet fully understood, there is a possibility that orientin may share some MOA with other flavonoids of similar structure such as luteolin and quercetin.

During dengue virus pathogenesis, monocytes and macrophages are essentially the target cells during infection (Durbin et al., 2008). The anti-inflammatory properties of orientin therefore may play a role in regulating inflammatory responses of the immune system. Dengue virus infection activates T-cells to overproduce pro-inflammatory cytokines such as TNF- $\alpha$ and IL-2, which eventually leads up to DHF and DSS. Orientin is known to regulate cytokine production in T-cells and therefore reduce inflammation caused by cytokine overproduction (Thangaraj and Vaiyapuri, 2017; Xiao et al., 2017). The proinflammatory high mobility group box-1 (HMGB1) proteins are also overproduced in macrophages and monocytes infected with dengue virus (Yang $\boldsymbol{e t}$ al., 2005) Studies on orientin also showed inhibition of HMGB1 protein activation of proinflammatory pathways such as NF- $\mathrm{KB} / \mathrm{ERK} / \mathrm{AKT}$, as well as production of TNF $\alpha$ and IL- $\beta$, which in turn was able to reduce inflammation caused by dengue virusactivated HMGB1 proteins (Yoo et al., 2014). Reduction of virus-induced inflammation was also observed through the regulation of complement hyperactivation of orientin. Hyperactivity of the complement system was thought to be stimulated by dengue IgG antibodies in secondary heterotypic infection (Halstead, 2015; Satyamitra et al., 2014)

To summarize, orientin may be able to exhibit anti-dengue activity through the antioxidative, antiviral, and anti-inflammatory properties. The antiviral effect of orientin against DENV2 have not been investigated and is therefore the main objective of this study. In addition, studies on monocyte cells are lacking, especially regarding its role in the pathogenesis of dengue virus. Hence, the present study was designed to investigate whether orientin exhibits any antiviral effect on human monocyte (THP-1) cells infected with DENV2.

\section{MATERIAL AND METHODS}

\section{Cell culture}

THP-1 cells were cultured in RPMI1640 medium (Gibco, USA) complete with $10 \%$ fetal bovine serum (FBS) (Gibco, USA), $100 \mathrm{U} / \mu \mathrm{L}$ penicillin, and $100 \mu \mathrm{g} / \mathrm{mL}$ streptomycin (Gibco, USA), and 10\% Fungizone (Gibco, USA). The cultures were grown at $37^{\circ} \mathrm{C}$ with $5 \% \mathrm{CO}_{2}$ until confluent.

\section{Preparation of orientin stock solution}

To prepare the stock solution, $5 \mathrm{mg}$ of pure orientin ( $\geq 98 \%$ ) compound (ChemFaces, China) was dissolved in $500 \mu \mathrm{L}$ dimethyl sulfoxide (DMSO) (Sigma Aldrich, USA) to make up a stock concentration of $22.3 \mathrm{mM}$. To prepare the working solutions of orientin for treatment of cells, the stock solution was dissolved in fresh complete RPMI1640 medium to make up to the desired concentrations.

\section{Collection of virus stock}

The $70 \%$ confluent HepG2 cells cultured in T-75 flasks (Corning, USA) were infected with $1 \mathrm{~mL}$ of DENV2 for six days. All the infected cultures were subjected to a freeze-thaw cycle up to 3 times to lyse the cells, the cultures were frozen at $80^{\circ} \mathrm{C}$ for 10 minutes, then thawed in a $37^{\circ} \mathrm{C}$-water bath until the liquid was all thawed. The supernatant from the cultures were pooled together and freeze-dried for $24 \mathrm{~h}$ until dry. The freeze-dried virus particles were resuspended in cell culture media and aliquoted into $1.5 \mathrm{~mL}$ microcentrifuge tubes. To prepare the working dilutions, DENV stock was diluted in fresh complete RPMI1640 medium before infecting the THP-1 cells.

\section{Determination of maximum non-toxic dose (MNTD) of orientin on THP-1 cells}

MNTD of orientin was performed to ensure the concentration of orientin administered did not kill the cells. The methods were similar to that described by Ling et al. (2014) and Tang et al. (2012), in which the control consists of cells only. THP-1 cells were first seeded at density of $5 \times 10^{5}$ cells/well in a 96 -well plate (Corning, USA). Orientin stock was dissolved in RPMI1640 medium and 5-fold serially diluted to make up final concentrations from $0.032 \mu \mathrm{M}$ to $100 \mu \mathrm{M}$ before adding to the cells. The treated cells were then incubated for $24 \mathrm{~h}$ at $37^{\circ} \mathrm{C}$ with $5 \%$ $\mathrm{CO}_{2}$. After 24 h, 3-(4,5- Dimethylthiazol-2-yl)-2,5-diphenyltetrazolium bromide (MTT) assay was performed to determine the cell viability. To perform MTT assay, $20 \mu \mathrm{L}$ of MTT reagent at the concentration of $5 \mathrm{mg} / \mathrm{mL}$ was added to each well, followed by $4 \mathrm{~h}$ of incubation. After incubation the cell medium was removed by pipetting, and $100 \mu \mathrm{L}$ of DMSO (Friendemann Schmidt, USA) was added. The plates were then incubated for another 5 minutes on an orbital shaker to dissolve the formazon crystals. Optical density (OD) was read on a microplate reader (Spectramax M3, Molecular Device, USA) at $570 \mathrm{~nm}$. From the data collected, a graph of percentage of cytotoxicity against the concentration of orientin was plotted. The MNTD was then determined by the highest concentration of orientin that exhibited $0 \%$ cytotoxicity.

\section{Determination of optimal DENV2 infective dose}

Virus infective dose was determined to identify the best virus dilution showing cytopathic effect (CPE) on THP-1 cells, which was identified by shrunken cells, which lacked clumps. Median tissue culture infective dose $\left(\right.$ TCID $\left._{50}\right)$ of the DENV2 stock was performed by infecting THP- 1 cells of density $1 \times 10^{5}$ cells/well with 10 fold serial dilution of the DENV2 stock (concentrations $10^{0}-10^{10}$ ). The cells were incubated for 6 days with constant observation for CPE. The wells were observed for CPE, and the $\mathrm{TCID}_{50}$ was calculated using the Reed and Muench calculator (Reed and Muench, 1938).

To determine the optimal infective dose, the cells were first seeded at $1 \times 10^{5}$ cells/well. The DENV2 stock was 2-fold serially diluted (undiluted to 128 -fold diluted) in RPMI1640 medium, before being added to the cells. Uninfected cells remain as controls. The THP- 1 cells were then incubated at $37^{\circ} \mathrm{C}$ with $5 \% \mathrm{CO}_{2}$ for a few days. Continuous observation of CPE was conducted using an inverted microscope (Nikon Eclipse Ti-U, Nikon, Japan). Observation for CPE continued until CPE formation no longer took place, the days post infection (dpi) determined was 2 days. MTT assay was then conducted to determine cell viability.

\section{In vitro antiviral assay of orientin against DENV2}

The antiviral assay was conducted by seeding THP-1 cells on a 96-well plate followed by incubation of orientin at MNTD with $100 \mu \mathrm{L}$ of virus at the respective dilutions as described previously for 1 hour. The orientin virus mixture was then added into the wells containing the cells. The cells were then incubated for 2 days Antiviral effect of orientin was performed by CPE observation using an inverted microscope, followed by MTT assay to determine the percentage of cell viability.

\section{Statistical analysis}

The data were collected from a set with three replicates and presented as means \pm standard deviation. The data was analyzed statistically by one-way ANOVA and Tukey's multiple comparison test with $P<0.05$ using Statistical Package for the Social Sciences (SPSS) to identify significant differences between the treatment groups. 


\section{RESULTS AND DISCUSSION}

\section{Determination of MNTD of orientin on THP-1 cells}

The objective of this study was to determine a suitable concentration of orientin that will not kill the THP-1 cells when administered in vitro. The orientin compound was 5-fold serially diluted to ensure proper identification of the MNTD. The following Figure 2 illustrates the different concentrations of orientin, and the extent of cytotoxicity exerted on THP-1 cells.

The MNTD of orientin on THP-1 cells was determined to be $0.053 \pm 0.006 \mu \mathrm{M}$ (Figure 2). As most studies involving bioactive compounds and DENV are largely conducted on HepG2, and Vero cell lines, studies on THP-1 cells are generally lacking, and hence not much of a comparison can be made (Kaushik et al., 2018) However, based on observations made from Figure 2, the MNTD of orientin on THP-1 cells are significantly lower when compared to different cell lines, such as SH-SY5Y and BV2 cell lines, showed higher values of $15-20 \mu \mathrm{M}$ (Kuruvilla $\boldsymbol{e}$ al., 2018; Law et al., 2014). This may suggest that orientin is more cytotoxic to THP-1 cells or that the cells may react differently or is more sensitive towards the compound.

At lower concentrations up to $0.053 \mu \mathrm{M}$, orientin cytotoxicity was lowest at $0.72 \%$, suggesting that orientin was able to enhance the cell viability. Enhancement in cell viability could be contributed by the radical scavenging property of orientin which protected the cells from damage from reactive oxygen species produced by mitochondrial enzymes (Lambert and Brand, 2009; Murphy, 2009). Yu et al. (2015) also reported that orientin was able to reduce oxidative stress by activation of the Nrf2 pathway, and hence inhibited the mitochondrial apoptotic pathway. However, an increase in concentration was accompanied with an increase in cytotoxicity against the cells, which resulted in lower percentage of cell viability. This might be due to the anti-proliferative properties of orientin that therefore exert cytotoxicity against the cells (Thangaraj and Vaiyapuri, 2017; Thangaraj et al. 2018). An et al. (2015) also explained that an increase of orientin concentration (5 $-80 \mu \mathrm{M})$ increased the apoptosis through the upregulation of p53 and downregulation of bcl-2 expressions. Hence, the increasing cytotoxicity might be reflected by the increasing apoptosis of the THP-1 cells.

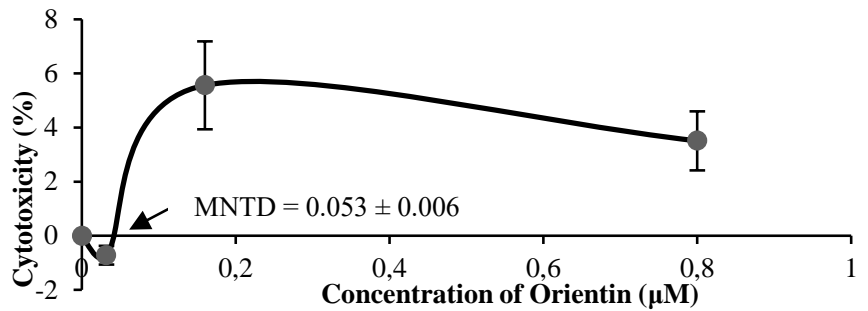

Figure 2 Percentage of cytotoxicity of orientin on THP-1 cells after $24 \mathrm{~h}$ incubation in different doses of orientin. Bar indicates means \pm standard deviation.

\section{Determination of DENV2 infective dose}

The virus infective dose determined the best or most suitable dilutions of DENV2 stock that infected the cells and produced CPE. CPE observation was conducted to identify the effect of DENV2 on THP-1 cells. The normal morphology of THP-1 cells showed regularly shaped, round cells, the cells may also appear brighte (Figure 3A). CPE in THP-1 cells were identified by observations of cells' shrinkage and lacking clumps (Figure 3B), as clumps indicated that the cells has undergone proliferations. CPE was observed on the wells with undiluted, 2-fold, and 4-fold diluted DENV2 stock (Figure 3B, 3C, and 3D respectively).

The dilutions were made from a stock with $3.16 \times 10^{2}$ TCID $_{50} / \mathrm{mL}$ of virus as calculated using the Reed and Muench method (1938). The method determines the $50 \%$ endpoint of serially diluted virus by calculating the difference in logarithms of the dilutions showing CPE (Ramakrishnan, 2016). As the Reed and Muench method uses a 10-fold dilution, the distance between the dilutions is too large, and hence a 2-fold dilution was conducted to determine the optimal virus infective dose, which was otherwise not observed when conducting 10-fold dilutions. This was done to ensure that the virus dilutions used were as accurate as possible by reducing the distance between the dilutions. The following Figure 4 shows the effect of DENV2 dilutions on the cell viability of THP-1 cells.

The percentage of cell viability for undiluted, 2-fold, and 4-fold diluted DENV2 were significantly reduced as compared to the uninfected cells. The cell death observed was most likely due to DENV2 infection, as observed from the appearances of CPE. However, DENV2 dilutions from 8-fold onwards showed percentage of viability of more than $50 \%$. These findings were in accordance with the lack of CPE as observed from Figure 3 for the respective dilution. In these treatments, the amount DENV2 virions might not be enough to significantly infect and kill the cells. Dilutions from 32-fold to 128 -fold showed percentage of viability higher than $100 \%$, which was up to $129.7 \%$. This apparent promoting effect could be due to the low multiplicity of infection (MOI) that comes with the low dose of virus. Low MOI was known to interfere with normal virion formation and hence stimulate monocytes or macrophages to proliferate (Smirnova et al., 2015)

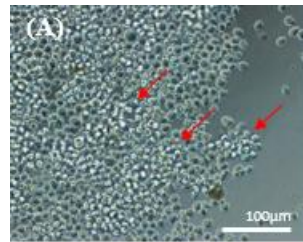

(B)

(C)
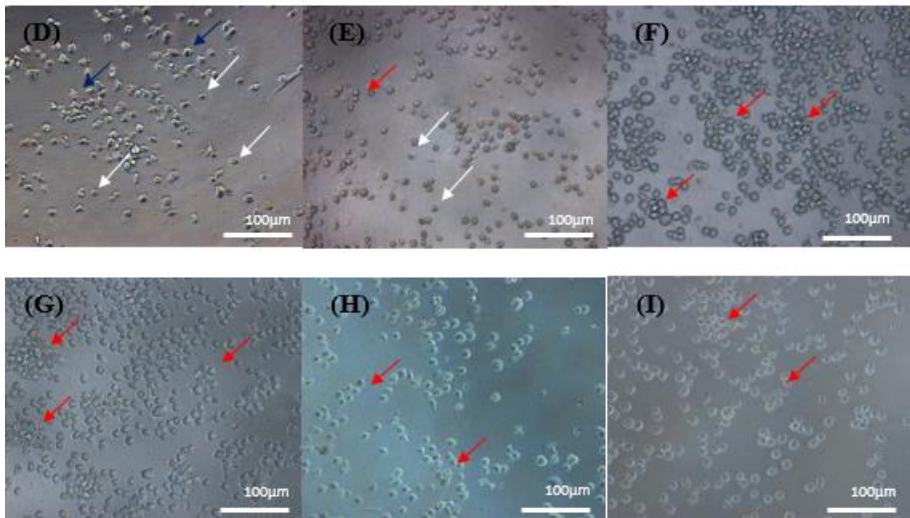

Figure 3 Light micrograph of THP-1 cells showing CPE and healthy THP-1 cell viewed under 200X magnification. (A): Uninfected THP-1 cells. Cells are round and regularly shaped, with clumps (red arrows) suggesting cell proliferation and higher cell density due to proliferation. (B): THP-1 cell infected with undiluted DENV2. Cells showing CPE were identified through shrinking of cells (white arrows) and lacked of clumps, as well as lower density of cells as compared to healthy cells. (C): THP-1 cells infected with 2-fold diluted DENV2. (D): THP-1 cells infected with 4-fold diluted DENV2. Plasma leakage can be observed in some of the cells (blue arrows), suggesting that cells were undergoing apoptosis. (E) THP-1 cells infected with 8-fold diluted DENV2. (F): THP-1 cells infected with 16-fold diluted DENV2. Presence of cell clumps and normal morphology of cells suggest virus dilution did not infect the cells. (G): THP-1 cells infected with 32 fold diluted DENV2. (H): THP-1 cells infected with 64-fold diluted DENV2. (I) THP-1 cells infected with 128-fold diluted DENV2.

Regarding the viral titer, the TCID $50 / \mathrm{mL}$ value of the DENV2 stock recorded in this study was considered low. One of the few factors that might have contributed could be the processes involved in concentrating the virus stock, such as repeated freeze-thawing, and freeze-drying processes used in this study (Ling et al., 2014) The unstable nature of RNA viruses such as Flavivirus, might have damaged during the procedures of repeated freeze-thawing (Costa $\boldsymbol{e t}$ al., 2011). In addition, the virus stock used to initiate the infection process might also contain low amounts of virus, or that the infectivity of virus has weakened over a long term of storage Diamond et al. (2000) also reported that viral strains, cell types, and viral passage number may affect the virus infectivity. The same DENV2 strain may exhibit higher infectivity on a different cell line, or vice versa. Furthermore, the presence of inhibitors in the culture medium, such as chelating agen ethylenediaminetetraacetate (EDTA), might reduce virus infectivity by binding with the virion particles (Manning and Collinst, 1979).

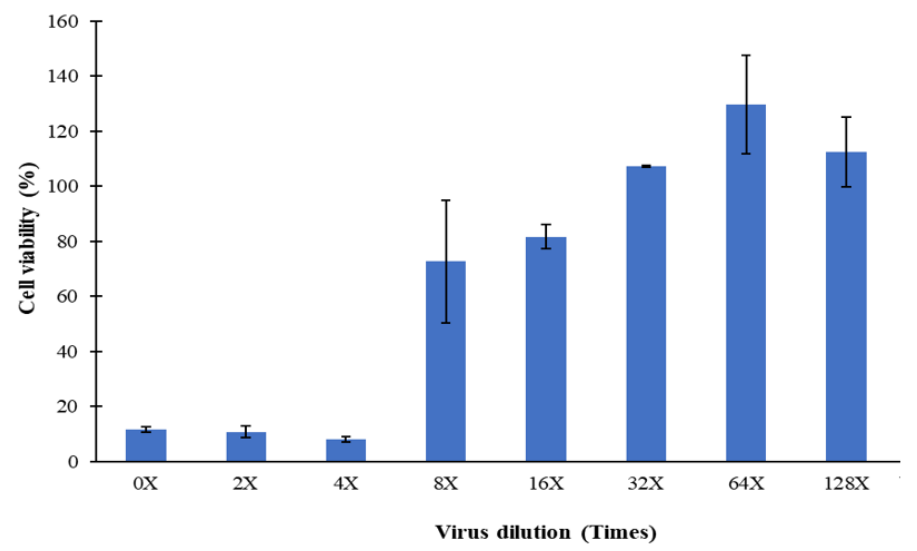

Figure 4 Effect of different DENV2 dilutions of $3.16 \times 10^{2} \mathrm{TCID}_{50} / \mathrm{mL}$ on the viability of THP-1 cells measured by MTT assay two days post infection (dpi). Bar indicates means \pm standard deviation.. 
The in vitro antiviral assay was conducted using values obtained from both parts, i.e. the MNTD of orientin and the infective dose of DENV2. The cells were observed for CPE and MTT assay was performed two days post infection to compare the effects of different treatments on the percentage of cell viability. The following Figure 5 represents the CPE observed in the four treatment groups. Microscopic observation revealed that treatments with orientin and DENV2 infection of the undiluted, 2-fold and 4-fold diluted stock showed CPE, while the same treatments with higher DENV2 stock dilutions did not show remarkable CPE. Apart from CPE observation, the antiviral study was conducted based on cell viability analysis using MTT assay after 2 days of treatment or infection. The following Figure 6 shows the effect of the different treatment groups at different virus dilutions on cell viability. From the results, it could be observed that orientin treatments as well as infection with undiluted, 2-fold, and 4-fold diluted DENV2 stock, had significantly reduced the cell viability as compared to the control cells. The treatment also did not show significant difference compared to infection with DENV2 only within the same group. This suggested that orientin at MNTD did not exhibit any antiviral effect against DENV2 infection. Treatments of cells with orientin at MNTD and infected with 8-fold, 16-fold, 64-fold and 128-fold diluted DENV2 showed no significant difference to the control cell $(P<0.05)$. However, treatment of orientin at 32-fold diluted DENV2 showed significantly higher cell viability, up to $145.93 \%$, compared to the control and virus only treatment. This might suggest that the proliferating effect of low virus MOI was further enhanced by the radical scavenging activity of orientin, which also promoted cell viability (Khan, 2012; Smirnova et al., 2015).

From the antiviral assay results, the infected and treated cells showed similar morphology and percentage of cell viability, it was suggested that orientin treatment on the infected cells did not produce any antiviral effects. Arguably, the dosage of orientin used in this study was very low, it could be possible that the MNTD of orientin was insufficient to inhibit virus infection in THP-1 cells. The antiviral activity of orientin against Para 3 virus was recorded to inhibit $\mathrm{CPE}$ at an $\mathrm{IC}_{50}$ of $11.7 \mu \mathrm{g} / \mathrm{mL}(26 \mu \mathrm{M})$ in HEp-2 cell culture (Li et al., 2002). The difference between the concentration of orientin was disparagingly large. A study conducted on naringenin, a flavanone naturally occurring in grapefruits and oranges, was reported to impair DENV maturation in human cell lines Huh7.5, as well as in primary $\mathrm{CD} 14^{+}$monocyte cells (Frabasile et al., 2017). The concentration used in the study was much higher compared to the concentration of orientin used in this present study. Huh7.5 cells were treated with $250 \mu \mathrm{M}$ and $125 \mu \mathrm{M}$ or naringenin, while primary monocyte cells were treated with a much lower concentration of $62.5 \mu \mathrm{M}$ of naringenin (Frabasile et al., 2017). Hence, the main issue with the present study might be largely due to the low MNTD of orientin administered. One may argue that the low dose of orientin might suggest that it is extremely cytotoxic to monocyte cells, and may attenuate the anti-inflammatory properties of THP-1 cells in response to viral infection. However, data on orientin cytotoxicity has been limited and this is the first study to investigate its effects on THP-1 cells, adverse cytotoxic effects were not anticipated to overcome the antiviral effects.
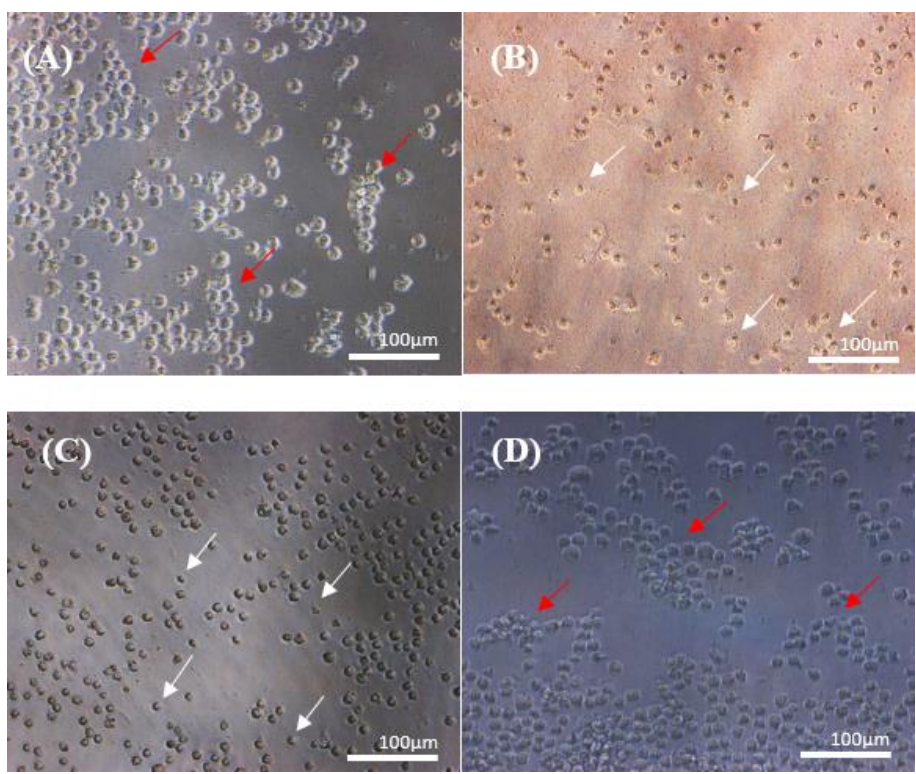

Figure 5 Light micrograph of the four treatment groups of THP-1 cells after two days post infection under 200X magnification. (A): Control THP-1 cells. (B): THP1 cells treated with orientin at MNTD and infected with virus dose showing CPE CPE observed by shrinking of cells (white arrows) and lacking clumps. (C): THP1 cells infected with virus showing CPE. (D): THP-1 cells treated with orientin at MNTD. Healthy cells are regularly round, with clumps (red arrows).

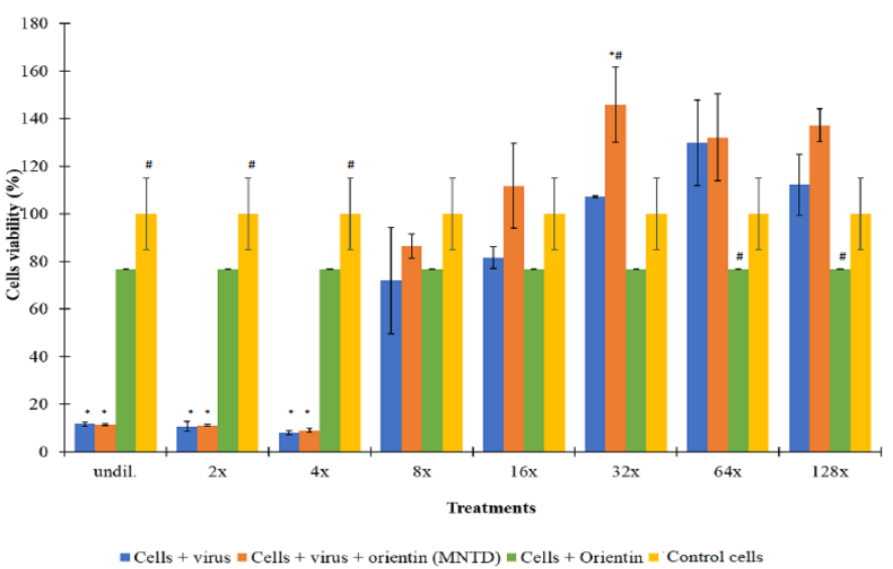

Figure 6 The antiviral activity of orientin determined by the viability of THP-1 cells as measured by MTT assay after 2 days post infection with DENV2. Bar indicates means \pm standard deviation. '*' indicates that the treatment was significantly different from control cells within the same treatment group (undiluted, $2 \mathrm{x}, 4 \mathrm{x}, 8 \mathrm{x}$ ) using one-way analysis of variance followed by Tukey's multiple comparison test at $p<0.05$. ' $\#$ ' indicates that the treatment is significantly different from the cells infected with virus only within the same treatment group (undiluted, $2 \mathrm{x}, 4 \mathrm{x}, 8 \mathrm{x}$ ) analysed using one-way analysis of variance followed by Tukey's multiple comparison test at $p<0.05$.

Previous studies have also been conducted on the extracts of Ocimum sanctum or other plant extracts containing orientin (Ling et al., 2014; Tang et al., 2012). This may suggest that the antiviral effects of orientin was observed through synergism with other flavonoids or compounds within the extract (Boominathan et al., 2014; Ali and Dixit, 2012). Furthermore, it was also argued that reactive oxygen species (ROS) produced by cells during viral infections is vital to assist in curbing viral replication by inducing apoptosis of infected cells (Valero et al., 2013). Apoptosis of infected cells, which was thought to limit viral replication, might be reduced by the antioxidative effects of orientin. Hence, regulation of ROS levels by orientin, which in turn reduces apoptosis, might have allowed viral replication to continue in infected cells. The regulation of Hsp70 chaperone, and miR-146a activity could be another underlying mechanism that might have enhanced the dengue virus replication in the presence of orientin (Padwad et al., 2010; Wu et al., 2013) Orientin might have upregulated Hsp70 chaperone or mir-146a expression, which was known to aid in viral RNA replication (Padwad et al., 2010; Wu et al., 2013) However, these require further in-depth analysis since no study has been done on the exact mechanisms of orientin, and interactions of the compound with other components of the cells are unknown.

Studies on dengue virus infection of cells revealed that the non-structural proteins (NS) are involved in RNA replication of the virus (Perera and Kuhn, 2008). A study by Qamar et al. (2014) identified NS1 glycoprotein as a potential target for blocking viral RNA replication. Blocking of glycosylation at Asn-130 residue of the dengue NS1 protein can disrupt the biological function of the protein and hence inhibit viral RNA replication. Qamar et al (2014) reported six flavonoids that were able to block glycosylation at Asn-130 and inhibit viral RNA replication. However, the structure of the six flavonoids were very different as compared to orientin, with larger substitution groups. The smaller size of the C-glycosyl substitution of orientin might not be able to strongly interact with the Asn-130 residue in the binding pocket, hence exerting weak to no virus inhibition effect.

In another study, the envelop structural proteins (E protein) of DENV are responsible in membrane fusion with host cells (Kuhn et al., 2002). Hinge region movement of domains I and II of the envelop protein are responsible in facilitating fusion with host cell membranes, hence binding at the hinge region by small molecules was hypothesized to be able to interrupt the fusion process. As was reported by Mir et al (2016) on the antiviral activity of quercetin in inhibiting membrane fusion of virions to host cell membranes. Both orientin and quercetin were structurally similar except for the lack of C-glycosyl substitution of quercetin, that is present in orientin. To a certain extent the conformation of orientin may not be able to facilitate the binding. The results in this study was also reflected in the study by Zandi et al (2011) where only quercetin was able to exhibit antiviral effect against DENV2. A similar in silico study conducted on the binding of flavonoids to DENV2 strains E protein binding pockets showed that baicalein, quercetin, and epigallocatechin gallate (EGCG) were able to interact with residues Ile40, Gly5, Asp98, Gly100 and Val151 of the E protein pocket, and therefore inhibit entry of virus (Ismail and Jusoh, 2017). The study suggested that the substitution groups and their arrangements affect the binding to the E protein pocket. Hence, the molecular conformations of orientin might be the contributing factor to the inability of the compound to inhibit dengue virus replication and fusion. 


\section{CONCLUSION}

In conclusion, orientin does not exhibit antiviral activity on THP-1 cells infected with DENV2 when administered at MNTD $(0.053 \mu \mathrm{M})$. In view that the MNTD determined in this study was rather low, which implied the high toxicity effect of orientin on THP-1 cells, it is predicted that the proinflammatory functions of the monocytes could be attenuated with orientin. Thus, more studies should be conducted to determine whether orientin is a suitable candidate as an antiviral agent against DENV infections. One aspect that can be conducted is by reducing the toxicity effects of orientin through structural modification. Furthermore, molecular docking simulations can also be conducted to identify the possible MOA of orientin, if any, in inhibiting the dengue virus. Antiviral effects of orientin can also be measured through viral RNA quantification using reverse transcription and q-PCR to identify possible virucidal effects of orientin instead of inhibitory effects via cell viability measurement. In addition, when selecting monocyte cells as an infection model, the analysis on inflammatory mediators and pathways of the nature of monocyte cells is also required. Regulations of inflammatory pathways such as NF- $\mathrm{B}$, AKT, and Toll pathway that involve inflammation and ROS production in viral pathogenesis may require quantification and analysis, as these pathways may have been upregulated or downregulated by interactions with orientin (Yoo et al., 2014; Pan et al., 2012; Ramirez and Dimopoulos, 2010) Furthermore, different types of monocytes may also be responsible in producing different types of cytokines and eliciting different antiviral responses. For example $\mathrm{CD} 16^{+}$monocytes were found to be the main producer of inflammatory cytokines TNF- $\alpha$, IL- $\beta$, and IL- 6 , which therefore might produce more dynamic changes in response to the treatments (Wong et al., 2012)

Acknowledgments: The author would like to thank Assoc. Prof. Leong Pooi Pooi from Universiti Tunku Abdul Rahman (UTAR) for generously providing the THP 1 cells. This study was supported by International Medical University [MBT2018(01)]

\section{REFERENCES}

Ahmad, A., Kaleem, M., Ahmed, Z., Shafiq, H. (2015). Therapeutic potential of flavonoids and their mechanism of action against microbial and viral infectionsA review. Food Research International, 77, 221-235. https://doi.org/10.1016/j.foodres.2015.06.021

Ahmad, N., Fazal, H., Ayaz, M., Abbasi, B.H., Mohammad, I., Fazal, L. (2011) Dengue fever treatment with Carica papaya leaves extracts. Asian Pacific Journal of Tropical Biomedicine, 1(4), 330-333. https://doi.org/10.1016/s2221 1691(11)60055-5

Ahmad, R., Suzilah, I., Wan Najdah, W.M.A., Topek, O., Mustafakamal, I., Lee, H.L. (2008). Factors determining dengue outbreak in Malaysia. Public Library of Science One, 13(2), e0193326. https://doi.org/10.1371/journal.pone.0193326

Ali, H., Dixit, S. (2012). In vitro antimicrobial activity of flavanoids of Ocimum sanctum with synergistic effect of their combined form. Asian Pacific Journal of Tropical Disease, 2, S396-398. https://doi.org/10.1016/S2222-1808(12)60189-3 Al-Sehemi, A.G., Irfan, A. (2017). Effect of donor and acceptor groups on radical scavenging activity of phenol by density functional theory. Arabian Journal of Chemistry, 10, S1703-1710. https://doi.org/10.1016/j.arabjc.2013.06.019

An, F., Wang, S., Tian, Q., Zhu, D. (2015). Effects of orientin and vitexin from Trollius chinensis on the growth and apoptosis of esophageal cancer EC-109 cells. Oncology Letters, 10(4), 2627-2633. https://doi.org/10.3892/ol.2015.3618

Bäck, A.T., Lundkvist, A. (2013). Dengue viruses - an overview. Infection Ecology and Epidemiology, 3, 19839. https://doi.org/10.3402/iee.v3i0.19839

Boominathan, S.P., Sarangan, G., Srikakulapu, S., Rajesh, S., Duraipandian, C., Srikanth, P. (2014). Antiviral activity of bioassay guided fractionation of Plumbago zeylanica roots against Herpes Simplex Virus Type 2. World Journal of Pharmacy Pharmaceutical Sciences, 3(12), 1003-1017.

Costa, E.C., Teixeira, M.F., da, S., Aguiar, T.D. de, F., Rolim, B.N., Romijn, P.C., Rocha, M.F.G. (2011). Rabies virus viability after short-term cryopreservation using cryoprotectant agents Viabilidade de vírus da Raiva após criopreservação de curto prazo com uso de agentes crioprotetores. Revista do Instituto Adolfo Lutz, 70(2), 106-112.

Cushnie, T.P.T., Lamb, A.J. (2005). Antimicrobial activity of flavonoids. International Journal of Antimicrobial Agents, 26(5), 343-356. https://doi.org/10.1016/j.ijantimicag.2005.09.002

Deen, J. (2016). The dengue vaccine dilemma: Balancing the individual and population risks and benefits. Public Library of Science Medicine, 13(11), e1002182. https://doi.org/10.1371/journal.pmed.1002182

Diamond, M.S., Edgil, D., Roberts, T.G., Lu, B., Harris, E. (2000). Infection of human cells by dengue virus is modulated by different cell types and viral strains. Journal of Virology, 74(17), 7814-7823. https://doi.org/10.1128/jvi.74.17.78147823.2000

Durbin, A.P., Vargas, M.J., Wanionek, K., Hammond, S.N., Gordon, A., Rocha, C., Balmaseda, A., Harris E. (2008). Phenotyping of peripheral blood mononuclear cells during acute dengue illness demonstrates infection and increased activation of monocytes in severe cases compared to classic dengue fever. Virology, 376(2), 429-435. https://doi.org/10.1016/j.virol.2008.03.028
Fan, W., Qian, S., Qian, P., Li, X. (2016). Antiviral activity of luteolin against Japanese encephalitis virus. Virus Research, 220, 112-116 https://doi.org/10.1016/j.virusres.2016.04.021

Flipse, J., Diosa-Toro, M.A., Hoornweg, T.E., van de Pol, D.P.I., UrcuquiInchima, S., Smit, J.M. (2016). Antibody-dependent enhancement of dengue virus infection in primary human macrophages; Balancing higher fusion against antiviral responses. Scientific Reports, 6, 29201. https://doi.org/10.1038/srep29201

Frabasile, S., Koishi, A.C., Kuczera, D., Silveira, G.F., Verri, W.A., Duarte dos Santos, C.N., Bordignon J. (2017). The citrus flavanone naringenin impairs dengue virus replication in human cells. Scientific Reports, 7(1), 41864 https://doi.org/10.1038/srep41864

Gubler, D.J. (2002). Epidemic dengue/dengue hemorrhagic fever as a public health, social and economic problem in the 21st century. Trends in Microbiology, 10(2), 100-103. https://doi.org/10.1128/9781555816940.ch1

Guzik, T.J., Korbut, R., Adamek-Guzik, T. (2003). Nitric oxide and superoxide in inflammation and immune regulation. Journal of Physiology and Pharmacology, 54(4), 469-487.

Halstead, S.B. (2015). Pathogenesis of dengue: Dawn of a new era $\begin{array}{lllll}\text { F1000Research, } & 4 & \text { (Faculty } & \text { Rev), }\end{array}$ https://doi.org/10.12688/f1000research.7024.1

Halstead, S.B. (2016). Licensed dengue vaccine: Public health conundrum and scientific challenge. American Journal of Tropical Medicine and Hygiene, 95(4), 741-745. https://doi.org/10.4269/ajtmh.16-0222

Ismail, N.A., Jusoh, S.A. (2017). Molecular docking and molecular dynamics simulation studies to predict flavonoid binding on the surface of DENV2 E protein. Interdisciplinary Sciences: Computational Life Sciences, 9(4), 499-511. https://doi.org/10.1007/s12539-016-0157-8

Kaushik, S., Kaushik, S., Sharma, V., Yadav, J. (2018). Antiviral and therapeutic uses of medicinal plants and their derivatives against dengue viruses. $\begin{array}{lll}\text { Pharmacognosy Reviews, 12(24), } & \end{array}$ http://dx.doi.org/10.4103/phrev.phrev_2 18

Khan, R,A. (2012). Evaluation of flavonoids and diverse antioxidant activities of

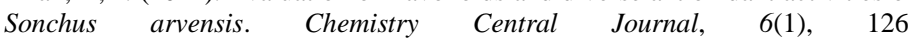
https://doi.org/10.1186/1752-153x-6-126

Krylova, N.V., Popov, A.M., Leonova, G.N. (2016). Antioxidants as potential antiviral agents for flavivirus infections. Antibiotics and chemoterapy, 61(5-6), $25-31$.

Kuhn, R.J., Zhang, W., Rossmann, M.G., Pletnev, S. V., Corver, J., Lenches, E., Jones, C.T., Mukhopadhyay, S, Chipman P.R., Strauss E.G., Baker, T.S., Strauss J.H. (2002). Structure of dengue virus: Implications for flavivirus organization, maturation, and fusion. Cell, 108(5):717-725. https://doi.org/10.1016/s00928674(02)00660-8

Kuruvilla, J., Ling, A.P.K., Voon, K.G.L., Koh, R.Y., Wong, Y.P. (2018) Investigating the autophagy mechanisms of orientin in lipopolysaccharidestimulated BV2 microglia cells. Biol Med, 10, 54. http://dx.doi/org/10.4172/09748369-C1-006

Lambert, A.J., Brand, M.D. (2009). Reactive oxygen species production by mitochondria. Mitochondiral DNA. Methods in Molceular Biology, Humana Press p. 165-181.

Law, B.N.T., Ling, A.P.K., Koh, R.Y., Chye, S.M., Wong, Y.P. (2014) Neuroprotective effects of orientin on hydrogen peroxide-induced apoptosis in $\mathrm{SH}$ SY5Y cells. Molecular Medicine Reports, 9(3), 947-954. https://doi.org/10.3892/mmr.2013.1878

Li, Y.L., Ma, S.C., Yang, Y.T., Ye, S.M., But, P.P.H. (2002). Antiviral activities of flavonoids and organic acid from Trollius chinensis Bunge. Journal of Ethnopharmacology, 79(3), 365-368. https://doi.org/10.1016/s03788741(01)00410-x

Ling, A.P.K., Khoo, B.F., Seah, C.H., Foo, K.Y., Cheah, R.K., Chye, S.M., Koh, R.Y. (2014). Inhibitory activities of methanol extracts of Andrographis paniculata and Ocimum sanctum against Dengue-1 Virus. International Conference on Biology, Environment, and Food Engineering, 47-52. https://doi.org/10.15242/iicbe.c814013

Lum, L., Ng, C.J., Khoo, E.M. (2014). Managing dengue fever in primary care: A practical approach. Malaysian Family Physician, 9(2), 2-10.

Lupu, R,, Menendez, J.A. (2006). Pharmacological inhibitors of Fatty Acid Synthase (FASN)--catalyzed endogenous fatty acid biogenesis: a new family of anti-cancer agents? Current Pharmaceutical Biotechnology, 7(6), 483-493. https://doi.org/10.2174/138920106779116928

Manning, J.S., Collinst, J.K. (1979). Effects of cell culture and laboratory conditions on Type 2 Dengue virus infectivity. Journal of Clinical Microbiology, 10(2), 253 - 239. https://doi.org/10.1128/jcm.10.2.235-239.1979

Mir, A., Ismatullah, H., Rauf, S., Niazi, U.H.K. (2016). Identification of bioflavonoid as fusion inhibitor of dengue virus using molecular docking approach. Informatics in Medicine Unlocked, 3,1-6. https://doi.org/10.1016/j.imu.2016.06.001

Mohd-Zaki, A.H., Brett, J., Ismail, E., L'Azou, M. (2014). Epidemiology of dengue disease in Malaysia (2000-2012): a systematic literature review. Public Library of Science Neglected Tropical Diseases, 8(11), e3159. https://doi.org/10.1371/journal.pntd.0003159 
Murphy, M.P. (2009). How mitochondria produce reactive oxygen species. Biochemical Journal, 417(1), 1-13. https://doi.org/10.1042/bj20081386

Mustafa, M.S., Rasotgi, V., Jain, S., Gupta, V. (2015). Discovery of fifth serotype of dengue virus (DENV-5): A new public health dilemma in dengue control. Medical Journal Armed Forces India, 71(1), 67-70. https://doi.org/10.1016/j.mjafi.2014.09.011

Ooi, V., Chan, P., Chiu, L., Sun, S., Wong, H. (2014). Antiviral activity of Chinese medicine-derived phytochemicals against avian influenza A (H5N1) virus. Hong Kong Medical Journal, 20(4), 37-41.

Padwad, Y.S., Mishra, K.P., Jain, M., Chanda, S., Ganju, L. (2010). Dengue virus infection activates cellular chaperone Hsp70 in THP-1 cells: Downregulation of Hsp70 by siRNA revealed decreased viral replication. Viral Immunology, 23(6), 557-565. https://doi.org/10.1089/vim.2010.0052

Pan, X., Zhou, G., Wu, J., Bian, G., Lu, P., Raikhel, A.S., Xi, Z. (2012). Wolbachia induces reactive oxygen species (ROS)-dependent activation of the Toll pathway to control dengue virus in the mosquito Aedes aegypti. Procedings of the National Academy of Science of the United States of America, 109(1), E23-31. https://doi.org/10.1073/pnas.1116932108

Pattanayak, P., Behera, P., Das, D., Panda, S.K. (2010). Ocimum sanctum Linn. A reservoir plant for therapeutic applications: An overview. Pharmacognosy Reviews. 4(7), 95-105. https://doi.org/10.4103/0973-7847.65323

Perera. R., Kuhn, R.J. (2008). Structural proteomics of dengue virus. Current Opinion in Microbiology, 11(4), 369-377. https://doi.org/10.1016/j.mib.2008.06.004

Prasain, J.K., Carlson, S.H., Wyss, J.M. (2010). Flavonoids and age-related disease: Risk, benefits and critical windows. Maturitas, 66(2), 163-171. https://doi.org/10.1016/j.maturitas.2010.01.010

Qamar, M.T.U., Mumtaz, A., Naseem, R., Ali, A., Fatima, T., Jabbar, T., Ahmad, Z., Ashfaq, U.A. (2014). Molecular docking based screening of plant flavonoids as Dengue NS1 inhibitors. Bioinformation, 10(7), 460-465. https://dx.doi.org/10.6026\%2F97320630010460

Rajapakse, S., Rodrigo, C., Rajapakse, A. (2012). Treatment of dengue fever. Infection and Drug Resistance, 5, 103-112. https://doi.org/10.2147/idr.s22613

Ramakrishnan, M.A. (2016). Determination of $50 \%$ endpoint titer using a simple formula. World Journal of Virology, 5(2), 85-86. https://doi.org/10.5501/wjv.v5.i2.85

Ramirez, J.L., Dimopoulos, G. (2010). The Toll immune signaling pathway control conserved anti-dengue defenses across diverse Ae. aegypti strains and against multiple dengue virus serotypes. Developmental and Comparative Immunology, 34(6), 625-629. https://doi.org/10.1016/j.dci.2010.01.006

Reed, L.J., Muench, H. (1938). A simple method of estimating fifty per cent endpoints. American Journal of Epidemiology, 27(3), 493-497. https://doi.org/10.1093/oxfordjournals.aje.a118408

Satyamitra, M., Mantena, S., Nair, C., Chandna, S., Dwarakanath, B.S. (2014). The antioxidant flavonoids, orientin and vicenin enhance repair of radiation-induced damage. Scholarena Journal of Pharmacy and Pharmacology, 1, 105. https://doi.org/10.18875/2375-2262.1.105

Scott, L.J. (2016). Tetravalent dengue vaccine: A review in the prevention of dengue disease. Drugs, 76(13), 1301-1312. https://doi.org/10.1007/s40265-0160626-8

Singh, P.K., Rawat, P. (2017). Evolving herbal formulations in management of dengue fever. Journal of Ayurveda and Integrative Medicine, 8(3), 207-210. https://doi.org/10.1016/j.jaim.2017.06.005

Smirnova, T.D., Danilenko, D.M., Ilyinskaya, E.V., Smirnova, S.S., Eropkin, M.Y. (2015). Impact of various multiplicity of infection of Influenza A virus on proliferation and apoptosis induction in cultrured cell lines of lymphocytic and monocytic origin (Jurkat, NC-37, THP-1 and U-937). Tsitologiia, 57(7), 526-532. Tang, L.I.C., Ling, A.P.K., Koh, R.Y., Chye, S.M., Voon, K.G.L. (2012) Screening of anti-dengue activity in methanolic extracts of medicinal plants. BMC Complementary and Alternative Medicine, 12, 3. https://doi.org/10.1186/1472 6882-12-3

Thangaraj, K., Natesan, K., Palani, M., Vaiyapuri, M. (2018). Orientin, a flavanoid, mitigates 1, 2 dimethylhydrazine-induced colorectal lesions in Wistar rats fed a high-fat diet. Toxicology reports, 5, 977-987. https://doi.org/10.1016/j.toxrep.2018.09.004

Thangaraj, K., Vaiyapuri, M. (2017). Orientin, a C-glycosyl dietary flavone, suppresses colonic cell proliferation and mitigates NF- $\kappa \mathrm{B}$ mediated inflammatory response in 1,2-dimethylhydrazine induced colorectal carcinogenesis. Biomedicine and Pharmacotherapy, 96, 1253-1266. https://doi.org/10.1016/j.biopha.2017.11.088

Valero, N., Mosquera, J., Añez, G., Levy, A., Marcucci, R., de Mon, M.A. (2013) Differential oxidative stress induced by dengue virus in monocytes from human neonates, adult and elderly individuals. Public Library of Science One, 8(9), e73221. https://doi.org/10.1371/journal.pone.0073221

Wong, K.L., Chen, W., Balakrishnan, T., Toh, Y.X., Fink, K., Wong, S.C. (2012) Susceptibility and response of human blood monocyte subsets to primary dengue virus infection. Public Library of Science One, 7(5):e36435. https://doi.org/10.1371/journal.pone.0036435

Wu, S., He, L., Li, Y., Wang, T., Feng, L., Jiang, L., Zhang, P., Huang, X. (2013). miR-146a facilitates replication of dengue virus by dampening interferon induction by targeting TRAF6. Journal of Infection, 67(4), 329-341. https://doi.org/10.1016/j.jinf.2013.05.003

Xiao, Q., Qu, Z., Zhao, Y., Yang, L., Gao, P. (2017). Orientin ameliorates LPSinduced inflammatory responses through the inhibitory of the NF- $\kappa$ B pathway and NLRP3 inflammasome. Evidence-Based Complementary and Alternative Medicine, 2017, 1-8. https://doi.org/10.1155/2017/2495496

Yang, H., Wang, H., Czura, C.J., Tracey, K.J. (2005). The cytokine activity of HMGB1. Journal of Leukocyte Biology, 78(1), 1-8. https://doi.org/10.1189/jlb.1104648

Yoo, H., Ku, S.K., Lee, T., Bae, J.S. (2014). Orientin inhibits HMGB1-induced inflammatory responses in HUVECs and in murine polymicrobial sepsis. Inflammation, 37(5), 1705-1717. https://doi.org/10.1007/s10753-014-9899-9

Yu, L., Wang, S., Chen, X., Yang, H., Li, X., Xu, Y., Zhu X. (2015). Orientin alleviates cognitive deficits and oxidative stress in A $\beta 1-42$-induced mouse model of Alzheimer's disease. Life Sciences, 121, 104-109. https://doi.org/10.1016/j.lfs.2014.11.021

Zandi, K., Teoh, B.T., Sam, S.S., Wong, P.F., Mustafa, M., Abu Bakar, S. (2011) Antiviral activity of four types of bioflavonoid against dengue virus type-2. Virology Journal, 8(1), 560. https://doi.org/10.1186/1743-422x-8-560 